\title{
After hours admission to icu - impact on mortality
}

\author{
HP Chan ${ }^{1,2^{*}}$, Z Puthucheary ${ }^{1,2}$, M Cove $^{1,2}$, A Mukhopadhyay ${ }^{1,2}$, J Phua ${ }^{1,2}$, HS Yip ${ }^{1,2}$ \\ From ESICM LIVES 2015 \\ Berlin, Germany. 3-7 October 2015
}

\section{Introduction}

Patients admitted to intensive care units (ICU) after hours have higher mortality rates in several studies. This effect is, however, negated in most studies upon correction for disease severity.

\section{Objectives}

We aim to explore differences in mortality between patients admitted during working hours $(8 \mathrm{am}-5 \mathrm{pm}$ on weekdays and $8 \mathrm{am}-11 \mathrm{am}$ on weekends) compared to those admitted after hours.

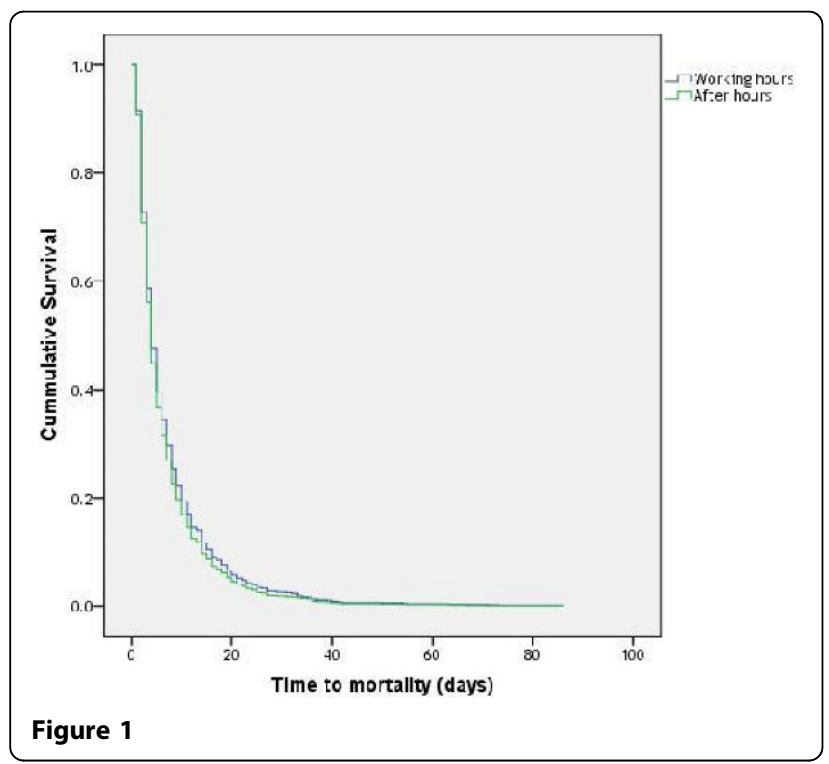

${ }^{1}$ National University Health System, Division of Respiratory and Critical Care Medicine, University Medicine Cluster, Singapore, Singapore

Full list of author information is available at the end of the article

\section{Methods}

This is a retrospective cohort study of admissions to a medical ICU in a tertiary teaching hospital between 2010-2014. All patients with known APACHE II scores were analysed. Primary outcome measure was that of ICU mortality adjusted for disease severity and secondary outcome measure was length of ICU stay.

\section{Results}

A total of 4266 admissions were included in this study. 1165 (27.3\%) were admitted during working hours while 3101 (72.7\%) were admitted after hours. There was no significant difference in APACHE II scores (24.0 \pm 8.7 working hours; $24.2 \pm 8.9$ - after hours, $\mathrm{p}=0.492$ ). Adjusted survival analysis did not demonstrate significant difference in mortality between the 2 groups (HR 0.923 , $95 \%$ CI $0.782-1.089, \mathrm{p}=0.343$ ) (figure 1). Patients

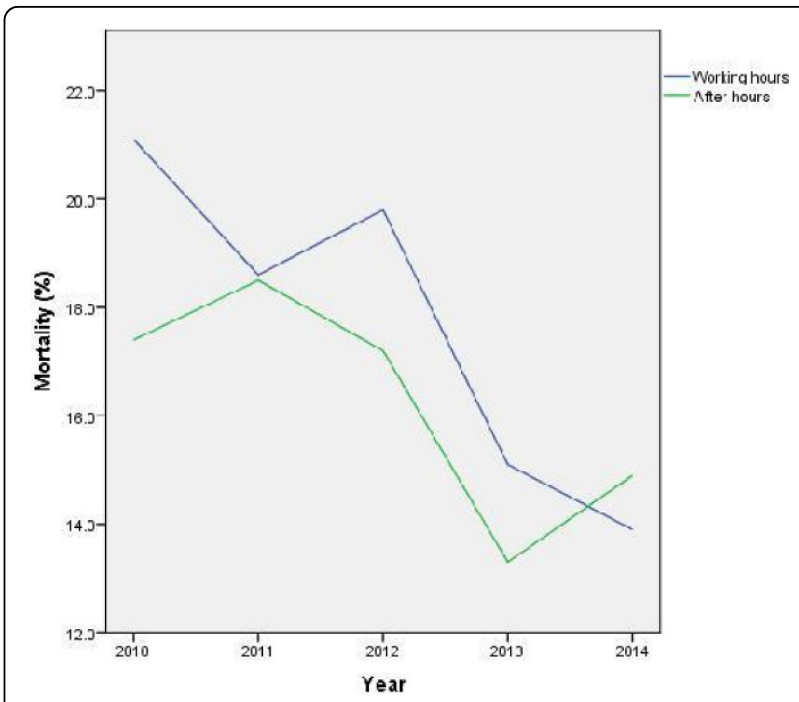

Figure 3

(c) 2015 Chan et al.; This is an Open Access article distributed under the terms of the Creative Commons Attribution License (http:// creativecommons.org/licenses/by/4.0), which permits unrestricted use, distribution, and reproduction in any medium, provided the original work is properly cited. 


\begin{tabular}{|c|c|c|c|c|c|c|c|}
\hline Year: & Group & Mortality & p-value & Length of stay & p-value & APACHE II scores & p-value \\
\hline \multirow[t]{2}{*}{2010} & Working hours & $15 / 71(21.1 \%)$ & \multirow[t]{2}{*}{0.519} & $6.6 \pm 0.8$ & \multirow[t]{2}{*}{0.573} & $23.0 \pm 8.1$ & \multirow[t]{2}{*}{0.643} \\
\hline & After hours & $23 / 132(17.4 \%)$ & & $7.6 \pm 1.0$ & & $22.4 \pm 7.3$ & \\
\hline \multirow[t]{2}{*}{2011} & Working hours & $45 / 242(18.6 \%)$ & \multirow[t]{2}{*}{0.980} & $7.2 \pm 0.6$ & \multirow[t]{2}{*}{0.142} & $23.1 \pm 8.2$ & \multirow[t]{2}{*}{0.027} \\
\hline & Afterhours & $105 / 567(18.5 \%)$ & & $6.3 \pm 0.3$ & & $24.6 \pm 9.5$ & \\
\hline \multirow[t]{2}{*}{2012} & Working hours & $53 / 268(19.8 \%)$ & \multirow[t]{2}{*}{0.350} & $6.7 \pm 0.5$ & \multirow[t]{2}{*}{0.322} & $24.7 \pm 9.2$ & \multirow[t]{2}{*}{0.921} \\
\hline & Afterhours & $122 / 709(17.2 \%)$ & & $6.1 \pm 0.2$ & & $24.8 \pm 9.0$ & \\
\hline \multirow[t]{2}{*}{2013} & Working hours & $36 / 238(15.1 \%)$ & \multirow[t]{2}{*}{0.468} & $6.5+0.4$ & \multirow[t]{2}{*}{0.200} & $24.5 \pm 8.8$ & \multirow[t]{2}{*}{0.150} \\
\hline & Afterhours & $96 / 724(13.3 \%)$ & & $6.0 \pm 0.2$ & & $23.5 \pm 8.5$ & \\
\hline \multirow[t]{2}{*}{2014} & Working hours & $48 / 346(13.9 \%)$ & \multirow[t]{2}{*}{0.627} & $6.9 \pm 0.5$ & \multirow[t]{2}{*}{0.045} & $23.9 \pm 8.8$ & \multirow[t]{2}{*}{0.519} \\
\hline & Afterhours & $145 / 970(14.9 \%)$ & & $5.7 \pm 0.3$ & & $24.3 \pm 8.9$ & \\
\hline
\end{tabular}

Figure 2

admitted after hours have a significantly shorter ICU stay $(5.8 \pm 0.1$ versus $6.5 \pm 0.2, p=0.007)$ if they survive their ICU stay. Year by year analysis also demonstrated no difference in mortality between cohorts (Figure 2) with a decrease in mortality seen in both in and out of hours admissions (figure 3).

\section{Conclusions}

Timing of acute admission had no impact on ICU mortality over a 4 year period. These data which are contradictory to some published observational studies may reflect working patterns among our medical and nursing staff, and that traditional definitions of "in-hours" may need to be revisited. The lack of mortality difference provides reassurance that our current workflows, and acute management protocols are unaffected by working hours, and has ramifications for manpower planning.

\section{Authors' details}

${ }^{1}$ National University Health System, Division of Respiratory and Critical Care Medicine, University Medicine Cluster, Singapore, Singapore. ${ }^{2}$ National University of Singapore, Department of Medicine, Yong Loo Lin School of Medicine, Singapore, Singapore.

Published: 1 October 2015

doi:10.1186/2197-425X-3-S1-A157

Cite this article as: Chan et al:: After hours admission to icu - impact on mortality. Intensive Care Medicine Experimental 2015 3(Suppl 1):A157.

\section{Submit your manuscript to a SpringerOpen ${ }^{\circ}$ journal and benefit from:}

- Convenient online submission

- Rigorous peer review

- Immediate publication on acceptance

- Open access: articles freely available online

- High visibility within the field

- Retaining the copyright to your article

Submit your next manuscript at $>$ springeropen.com 